\title{
A study of the relationship between the migration of image silver and perceived yellowing of silver gelatine photographs
}

(2) CrossMark

Jacqueline Moon ${ }^{1}$ and Katherine Curran ${ }^{2 *}$ (1)

\begin{abstract}
Silver gelatine photographs were the most dominant photographic process of the twentieth century from the 1880s until the 1960s. They are prone to yellowing, mirroring and fading which is largely attributed to the effects of pollutants, relative humidity and residual processing chemicals. Experts in the conservation of photographs claim they can determine the causes of deterioration with the naked eye: the effects of humidity result in a more yellowed appearance, whilst the presence of residual chemicals results in a redder appearance. This work aims to investigate if the same deterioration processes can be diagnosed in photographic prints with a spectrophotometer by addressing two questions: (1) In new and artificially aged silver gelatine photographs is it possible to distinguish between discolouration caused by silver migration and that caused by the presence of residual sulfur? (2) What are the complexities of applying these findings to historic photographs? A set of test photographs, some well processed and some insufficiently washed was developed and artificially aged. These were compared to a small collection of historical photographs of different ages, paper types and image colours. Samples were assessed using visual observation, residual silver and hypo spot tests, colour measurements including $L^{*} a^{*} b^{*}$ and reflectance spectra, Fourier transform infra-red (FTIR) spectroscopy and transmission electron microscopy (TEM). After artificial ageing the well processed test photographs were more yellowed, TEM indicated that this was due to colloidal silver formation. The insufficiently washed test photographs were more red but also darker, TEM showed these samples to have more homogeneous silver filaments, thought to be due to silver sulfide formation. The results for the historical photographs were similar but more subtle. A larger sample set is needed to investigate this more extensively. Further investigation on historical samples, with colour measurements and residual silver and fixer spot tests will take place.
\end{abstract}

Keywords: Silver gelatine photograph, Yellowing, Image silver, Silver filaments, Colloidal silver, Transmission electron microscopy, Spectrophotometry, Residual silver spot test, Thiosulfate spot test

\section{Introduction}

Black and white silver gelatine photos were the most dominant photographic process of the twentieth century from their introduction in the 1880s until the 1960s when they were superseded by chromogenic photographs and then digitally printed images. The National Archives, UK, where this research was undertaken, holds an estimated

\footnotetext{
*Correspondence: k.curran@ucl.ac.uk

${ }^{2}$ UCL Institute for Sustainable Heritage, Bartlett School of Environment,

Energy and Resources, University College London, London, UK

Full list of author information is available at the end of the article
}

six million photographs, of which approximately $90 \%$ are silver gelatine.

A developed out silver gelatine photograph is composed of an image forming layer, a binder and a support layer. The image can have a variety of image tones from brown, to purplish or grey-black, whilst non-image areas may vary from bright white to cream, ivory and beige [1]. The image may be glossy, satin or matt and the surface texture may be smooth or granular [2]. A typical processed silver gelatine print on fibre-based paper has a light sensitive emulsion composed of silver particles suspended in gelatine, attached to a paper base coated with 
a baryta layer: barium sulphate in gelatine. Resin coated papers were introduced in the 1960s to reduce washing and drying times and minimise paper cockling [3]. The light sensitive emulsion is attached to a paper base coated with polyethylene (PE). The PE on the image side contains a pigmented layer, usually titanium dioxide.

The size and character of silver clumps varies according to the emulsion making technique and the developer used [4]. High relative humidity, residual processing chemicals and pollutants cause changes to the image silver which our naked eye perceives as yellowing, mirroring and fading, all of which indicate image deterioration. This operates through the ionisation of elemental silver which can migrate through gelatine and be reduced to form either colloidal silver (see below), or silver sulfide [5-7].

Colloidal silver is used in many applications from photovoltaics to biological and chemical sensors. It consists of small spherical silver particles which have unique optical properties. The particles undergo surface plasmon resonance (SPR); in which conductive electrons on the surface collectively oscillate when excited by visible light [8]. The colours scattered by colloidal silver depend on the size, shape, medium and the presence of impurities [9]. In film and photographs they can range from 50 to several hundred $\AA$ in diameter [10]. As particles increase in diameter from 10 to $60 \mathrm{~nm}$, the peak maximum in their extinction spectra shifts from the blue towards the red, giving media containing such particles a visual appearance that shifts from yellow to red to purple and violet [9]. Silver sulfide formation occurs due to the reaction of silver ions with residual processing chemicals such as sodium thiosulfate. In thin films or colloidal particles, silver sulfide will appear yellow but in experimental work using dilute aqueous sulfide the absorption spectrum of colloidal silver was affected by oxidisation resulting in a brown appearance [9].

Image deterioration has largely been assessed using the naked eye, spectrophotometry, TEM and blue filter densitometry, with the instrumental approaches largely applied to film rather than photographic prints to date. Observations by eye require significant experience and can be subjective. Experts claim they can ascribe different causes to different image hues. Weaver [7] and Torigoe [6] used the terms 'yellow' and 'yellow-orange' to describe the effect of oxidising agents on silver gelatine photographs, and 'yellow-brown' and 'brownishred' to describe sulfide formation; while James [11] used 'bronzing' to describe the effects of relative humidity. Spectrophotometry has been used to confirm the similarity of orange spots on microfilm to laboratory prepared coatings of colloidal silver [12] and to study the transmission densities of silver images on film exposed to oxidising agents at different wavelengths [11]. Work has also been undertaken in the field of optics on the spectral absorption of colloidal silver in gelatine [13, 14]. In these examples the measurements were taken from film, not photographic prints as studied in this work. TEM has been widely used to study the effects of chemicals and environmental conditions on silver filaments [15-17] again largely on film.

Blue filter densitometry is traditionally used for yellowness evaluation [18] and has been used in both film and prints; Reilly has used it to study albumen prints [19], whilst Nishimura [20] has used it in the development of the photographic activity test (PAT). It cannot provide information on reddening.

This study sets out to explore the relationships between colour changes, silver image migration and silver sulfide formation in silver gelatine photographs. This addresses an observed gap in the literature whereby most previous work has focussed on film, rather than photographic prints. It also seeks to understand if observations made by experts can be quantified using spectrophotometry. If this was possible then simple colour measurements could be used to assess photographs without resorting to destructive testing and non-specialists could diagnose deterioration causes and by implication inform conservation decisions in storage, housing, display and conservation treatment.

It will address two questions:

1. In new and artificially aged silver gelatine photographic prints, is it possible to distinguish between discolouration caused by migration of image silver and that caused by the presence of residual sulfur.

2. What are the complexities of applying these findings to historic photographs?

A series of artificially aged and historical samples were evaluated using visual observation, residual silver and hypo spot tests, colour measurements including L*a*b* and reflectance spectra, fourier transform infra-red (FTIR) spectroscopy and transmission electron microscopy (TEM).

\section{Methods}

\section{Test photographs}

Three different photographic papers with optical brightening agents; a fibre-based glossy Fomabrom variant III multi grade paper, a fibre-based matt Fomabrom variant II2 multi grade paper and a resin-coated paper Ilford Multigrade IV resin coated, were processed using the following chemicals: 
- Developer: Tetenal Eukobrom black and white developer, dilution 1:9.

- Stop bath: Tetenal Indicet odourless stop bath, dilution 1:19.

- Fixer: Tetenal Superfix plus rapid fixer, dilution 1:4

- Wash: washing in running tap water for $15 \mathrm{~min}$.

The Fomabrom variant III and 112 are manufactured using a silver chloro-bromide emulsion that gives a neutral to medium-warm tone. Multigrade IVRC has a bright base tint with a cool-to-neutral tone. No manufacturer's information is available for the Multigrade IVRC.

The chemicals are supplied in concentrated form and were diluted as per the instructions on the bottles for the different paper types. Six photographs were made on each of the three paper types, totalling 18 test photographs. For each paper type three samples were well processed and three samples were insufficiently-washed. The well processed samples were processed according to the manufacturers instructions and then washed according to the times recommended by BS ISO 18929:2012 [18]. The insufficiently washed samples were not properly washed after processing. They were dipped and then agitated for $5 \mathrm{~s}$.

The image consisted of a 21-step projection scale $4 \times 5 \mathrm{in}$. The scale has 21 regularly stepped and numbered density increases from the transparent to the opaque and is used to evaluate the correct exposure and processing times in the lithographic and photographic printing industries. The scale was used to provide density areas large enough to be measured by a spectrophotometer and to facilitate visual observations.

\section{Historical samples}

Four historical photographs of different ages, paper types and perceived yellowing were selected, see Table 1 .

\section{Artificial ageing}

One test photo from each paper and processing type was aged at $50{ }^{\circ} \mathrm{C}$ and $70 \% \mathrm{RH}$ and $50{ }^{\circ} \mathrm{C}$ and $90 \% \mathrm{RH}$ in a Binder climatic chamber KBF for 1 month. The samples were attached by cotton thread to sheets of polyester $\left(\right.$ Melinex $\left.^{\mathrm{TM}}\right)$ and laid horizontally.

Table 1 Names and dates of the historical samples

\begin{tabular}{ll}
\hline Sample name & Date \\
\hline Street scene (SS) & Early 20th century (speculated from the image) \\
Ceremony (C) & 20th century (speculated from the image) \\
Aeroplane (A) & $29 / 10 / 1945$ \\
$\begin{array}{l}\text { Crumpled manuscript } \\
\text { (CM) }\end{array}$ & $14 / 03 / 1963$ \\
\hline
\end{tabular}

\section{Ultraviolet visible induced fluorescence}

All the photographs were examined with ultraviolet visible induced fluorescence at $366 \mathrm{~nm}$. This was to detect the presence or absence of optical brightening agents.

\section{Spot tests lodine potassium iodide}

The iodine potassium iodide solution was prepared and performed according to Odegaard [21] on a test strip from an un-aged fibre based matt test photograph and a historical matt silver gelatine photograph. This was to determine if the matting agents were starch or colloidal silica.

\section{Kodak silver test solution $S T_{-1}$ and Kodak hypo test solution} $H T_{-2}$

Kodak silver test solution $\mathrm{ST}_{-1}$ and Kodak hypo test solution $\mathrm{HT}_{-2}$ were prepared and executed according to Lavédrine [22]. Test strips were cut from the un-aged and aged test photographs, and the historical prints. The silver test solution is used to detect prints that have been washed in exhausted fixing baths. The hypo test solution is used to detect prints that have been insufficientlywashed and consequently retain thiosulfate. Both test solutions form irreversible stains and are therefore not well suited to historical collections. The silver test is evaluated as positive if anything more than a simple cream shade results, the hypo test was evaluated using a colour card which was only available online. The ratings for the hypo test are 1-4 as follows: barely perceptible 1 , slight 2 , moderate 3 and heavy 4 .

\section{Visual observations}

A box was made from grey archival cover paper $(320 \mathrm{H} \times 825 \mathrm{~W} \times 720 \mathrm{D} \mathrm{mm})$ to view the samples based on a method has been used for the improved damage assessment for parchment [23]. There were five observers. The observers were conservators and conservation technicians specialising in archival materials but not photographs.

The samples were compared using a scale that assesses colour change as imperceptible, barely perceptible, slight, moderate or heavy, developed by Honda [24]. The test photographs were rated by comparison between non aged and artificially aged. The historical samples were evaluated for yellowing by comparing the light, mid and dark image tones.

\section{Colour measurements}

Reflectance spectra, status A(B) densitometry and L*a*b* values were taken using a Konica Minolta spectrophotometer CM-2600d (SCE, 100\% UV included, SAV $3 \mathrm{~mm}$, Primary D65, observer $10^{\circ}$ ) manufactured in Japan. The 
$\Delta \mathrm{L}, \Delta \mathrm{a}, \Delta \mathrm{b}$ and status A diff. (B) were calculated using SpectraMagic $^{\mathrm{TM}}$ NX software using CIEDE2000 for the test photographs. The colour differences were not relevant to the historical samples.

A template was made with a hole-punch matched to the diameter of the spectrophotometer. Multiple measurement sites were selected for the test photographs: steps $21,14,11,08,05,01$. Each site was measured three times before and after ageing. The relative standard deviations (RSD) of the colour measurements were calculated for steps $5,8,11$ and 14 to determine if colour changes were actual changes after ageing and not due to a slight misplacement of the template. Three repeat measurements were taken of each, the sample removed and replaced in the template. The RSD of the majority of samples were $0-1 \%$, but ranged from 0 to $3 \%$. The error bars in Figs. 5, 8 and 9 show the RSD.

\section{Fourier transform infra-red spectroscopy}

In order to study the effects of artificial ageing on silver gelatine photographs, attenuated total reflectance Fourier transform infra-red spectroscopy (ATR FTIR spectroscopy) was used on four test photographs. ATR FTIR spectroscopy was performed with a Nicolet 380 FT-IR spectrometer by Thermo Scientific with a diamond crystal and OMNIC Lite Software. Sixty-four scans at a resolution of $4 \mathrm{~cm}^{-1}$ over the wavenumber range 4000 $375 \mathrm{~cm}^{-1}$, were taken from a non image area of nine test photographs which exhibited different degrees of yellowing. The ratio of the amide I and II peaks (found at approx. 1650 and $1550 \mathrm{~cm}^{-1}$ respectively) [25] were compared.

\section{Transmission electron microscopy (TEM)}

Sections $1 \mathrm{~mm} \times 2 \mathrm{~mm}$ were cut and fixed overnight in a solution of $2 \%$ glutaraldehyde in distilled water. The sections were washed in distilled water and then gradually dehydrated in a series of graded ethanol-water mixtures to $100 \%$ ethanol and infiltrated with Agar 100 resin mix (Agar scientific). The sample was then blocked out and hardened. Ultra-thin sections of $80 \mathrm{~nm}$ thickness were cut on a Reichert Ultracut-S microtome with a Diatome diamond knife, collected on Formvar-coated $2 \times 1 \mathrm{~mm}$ slotted copper grids and viewed in a JEOL 1010 transmission electron microscope. Images were recorded using a Gatan Orius camera.

Image J was used to assess the size and quantity of silver particles in the image layer. TEM images at $\times 10,000$ were used to calculate the approximate number of particles in steps 5 and 11 before ageing. Images at $\times 150,000$ were used to calculate the area of the silver filaments and the size and number of colloidal silver particles. An average of nine images were taken from each cross section at $\times 150,000$ with the exception of the un-aged well processed and insufficiently washed fibre-based matt samples of which there were three of and two respectively. Colloidal particles were categorised by diameter according to Wiegel (Ware), with a particular focus on a diameter of $0-25 \mathrm{~nm}$.

\section{Results and discussion \\ Test photographs before ageing}

The following results focus on one paper type, fibre based matt. The reader should assume agreement with other paper types unless otherwise mentioned. The data from other paper types is presented in the electronic supplementary information. The details are provided under Availability of data and materials at the end of the article.

\section{Visual observations and spot tests}

Two hours after processing the insufficiently washed samples on fibre-based papers had started to discolour, see Fig. 1 and emitted a sulphurous smell. A warmer image tone was most noticeable in the lighter step wedges 11-21 of the fibre-based papers, whilst the resincoated papers had barely perceptible yellowing in the non-image areas only. The insufficiently washed samples on all paper types reacted positively to the hypo spot test indicating that the warmer tones in the step wedges were caused by excess sodium thiosulphate (used as fixer) reacting with the image silver to form silver sulfide $[1,26,27]$. The formation of silver sulfide can occur at both room temperature [15] and elevated conditions. The resin coated photograph reacted the least indicating that the polyethylene coating inhibited the retention of sodium thiosulfate.

Photographs with residual fixer should typically show white highlights but faded and yellowed image tones [26, 27]. This is due to the removal of the unexposed silver from the highlights. Contrary to the literature the background of the insufficiently washed test photographs had slightly yellowed. A TEM image of an un-aged insufficiently washed test photograph was examined and showed a lack of either silver filaments or colloidal silver particles, so silver sulfide formation was discounted.

The background yellowing was therefore attributed to a thiosulfate and gelatine interaction as staining of gelatine is well known when in contact with poor quality housing materials [20].

The versos of the insufficiently washed fibre based samples had a ghost image illustrating the migration of silver ions [28] and is thought to be brown silver sulfide.

The matting agent in these photographs tested negative to the iodine potassium iodide test and is thought to be colloidal silica. 


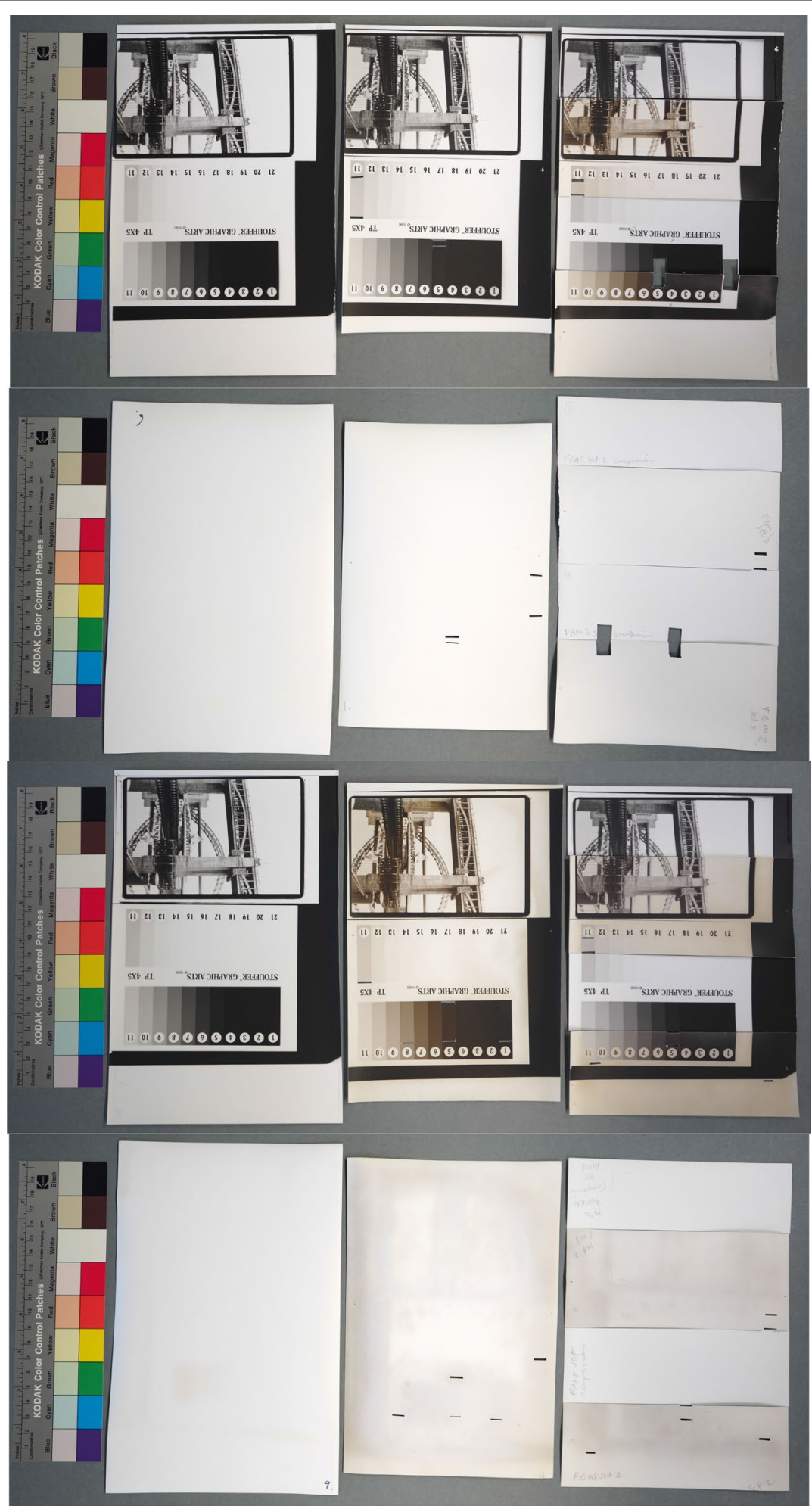

Fig. 1 Fibre based matt test photographs before and after ageing at $50{ }^{\circ} \mathrm{C}$ and $70 \% \mathrm{RH}$ and $50{ }^{\circ} \mathrm{C}$ and $90 \% \mathrm{RH}$. First row left to right: well processed un-aged, aged $50^{\circ} \mathrm{C}$ and $70 \% \mathrm{RH}$, aged $50^{\circ} \mathrm{C}$ and $90 \% \mathrm{RH}$, second row left to right: corresponding versos of row one, third row: insufficiently washed un-aged, aged $50{ }^{\circ} \mathrm{C}$ and $70 \% \mathrm{RH}$, aged $50{ }^{\circ} \mathrm{C}$ and $90 \% \mathrm{RH}$, fourth row: corresponding versos of row three. Two of the samples are cut to allow direct comparison of the same photograph 


\section{Spectrophotometer measurements}

The $L^{*} \mathrm{a} \mathrm{b}^{*} \mathrm{v}$ values of the well processed and insufficiently washed test photographs were compared before ageing. The insufficiently washed fibre-based glossy (step 21-01) and matt photographs (step 21-08) were less blue and less red, see Fig. 2. This corresponded to visual observations of yellowing in relation to the well processed. The impact of optical brightening agents on colour measurements was seen as negative $b *$ values.

\section{Transmission electron microscopy}

The silver filaments in the test photographs for all paper types and processing methods were relatively evenly distributed between the baryta layer and the starch coating. The individual filaments making up each filament bundle in the well processed photographs were longer whilst the insufficiently washed samples appeared to be more separated and in some cases shorter or rounder, see Fig. 5. This could be due to the breakdown of the silver particles by the thiosulfate. The insufficiently washed resincoated paper behaved slightly differently, their filaments appeared a little longer.

There was some variation in the size of the silver particles in all samples, but they appeared to correlate with images by Lavédrine and Reilly [1,29] on photographic prints showing the filament bundles to be on average $0.5 \mu \mathrm{m}$ across. There were approximately 760,000 silver particles per $\mathrm{mm}^{2}$ in step 5 of the well processed fibre-based glossy paper and 49,500 silver particles per $\mathrm{mm}^{2}$ in the well processed fibre-based glossy paper step 11. This would be expected as step 5 is darker and consequently has more silver. This was in a cross section $80 \mathrm{~nm}$ thick.

\section{Test photographs after ageing}

\section{Visual observations and spot tests}

Table 2 shows the visual observations and the spot test results made of the well processed and insufficiently

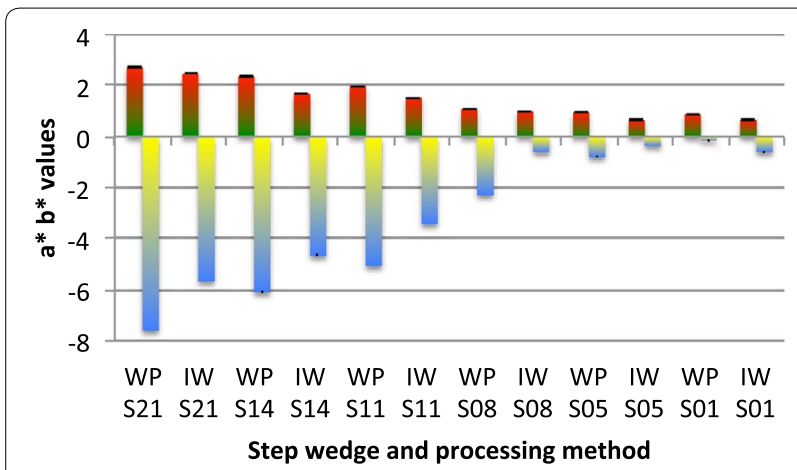

Fig. 2 The $a^{*} b^{*}$ values of the un-aged well processed (WP) and insufficiently washed (IW) fibre based matt photographs washed photographs after degradation at $50{ }^{\circ} \mathrm{C}$ and $70 \%$ and $50{ }^{\circ} \mathrm{C}$ and $90 \% \mathrm{RH}$. It can be seen that for the well processed photographs, for all paper types no clear change was observed on the recto at $50{ }^{\circ} \mathrm{C}$ and $70 \% \mathrm{RH}$ whilst light discolouration was observed on the versos after degradation. After degradation at $50{ }^{\circ} \mathrm{C}$ and $90 \% \mathrm{RH}$ however, more significant colour changes were observed. The well processed samples aged at $50{ }^{\circ} \mathrm{C}$ and $90 \% \mathrm{RH}$ looked more yellow green in comparison to the insufficiently washed samples which looked more reddish brown after degradation at $50{ }^{\circ} \mathrm{C}$ and $70 \% \mathrm{RH}$, and purplish brown after degradation at $50{ }^{\circ} \mathrm{C}$ and $90 \% \mathrm{RH}$. These findings correspond to previous observations on both film and photographs that discolouration due to the impact of high relative humidity gives a yellowish appearance, while that due to the presence of residual processing chemicals gives a redder appearance.

Image discolouration was less pronounced in the resin coated photographs in the case of both the insufficiently washed and well processed samples. Again it seems logical that the polyethylene layer has reduced moisture uptake by the gelatine, inhibiting sulfur discolouration, silver ionisation and migration. For the same reason it is worth noting that tidelines were observed on the unexposed areas of the insufficiently washed resin coated photograph aged at $50{ }^{\circ} \mathrm{C}$ and $70 \% \mathrm{RH}$ (adjacent to some of the densest image areas) and a mirrored fingerprint.

An increase in the background staining was observed on the recto of the insufficiently washed samples. Brown staining is attributed to excess thiosulfate, especially at elevated temperatures, suggesting the following reaction may be taking place: $\mathrm{S}_{2} \mathrm{O}_{3}{ }^{2-}+2 \mathrm{H}^{+} \rightarrow \mathrm{SO}_{2}$ (g) $+\mathrm{S}(\mathrm{s})+\mathrm{H}_{2} \mathrm{O}$ and in turn leading to $\mathrm{SO}_{2}$ (g) $+\mathrm{H}_{2} \mathrm{O} \rightarrow \mathrm{H}_{2} \mathrm{SO}_{4}$. Although the contribution of yellowing from gelatine staining to the yellowing measurements of the image areas cannot be accounted for, this excess of thiosulfate, as shown later, was found to inhibit silver migration in the insufficiently washed fibre-based photographs enabling different causes of discolouration i.e. silver sulfide formation and silver migration, to be distinguished from one another.

The spot tests indicated a decrease in excess thiosulfate as the $\mathrm{RH}$ increased from 70 to $90 \% \mathrm{RH}$, suggesting that as the humidity increased the thiosulfate was exhausted through the formation of silver sulfide. The spot tests also demonstrate that little residual thiosulfate was present in the well processed photographs, before or after degradation. Finally they also indicate that silver, silver thiosulfate and thiosulfate were less strongly retained by resin-coated papers compared with fibre-based, reducing the opportunity for colour change due to silver sulfide formation. 
Table 2 Visual observations and spot test results of the fibre based matt test photographs before and after artificial ageing

\begin{tabular}{lllllll}
\hline Sample & \multicolumn{2}{l}{ Visual observations $^{\mathbf{a}}$} & & & \multicolumn{2}{l}{ Spot tests } \\
\cline { 2 - 3 } & Border & Image & Verso & & Silver & Residual fixer (thiosulfate) \\
\hline Well processed un-aged & Imperceptible & Imperceptible & Imperceptible & No & Slight [2] \\
Well processed aged $50^{\circ} \mathrm{C}$ and $70 \% \mathrm{RH}$ & Imperceptible & Imperceptible & Barely perceptible & No & Slight [2] \\
Well processed aged $50^{\circ} \mathrm{C}$ and $90 \% \mathrm{RH}$ & Slight & Heavy & Slight & & No & Slight [2] \\
Insufficiently washed un-aged & Barely perceptible & Barely perceptible & Moderate & & Perceptible & Heavy [4] \\
Insufficiently washed aged $50^{\circ} \mathrm{C}$ and $70 \% \mathrm{RH}$ & Moderate & Heavy & Heavy & & No & Heavy [4] \\
Insufficiently washed aged $50^{\circ} \mathrm{C}$ and $90 \% \mathrm{RH}$ & Heavy & Slight & Heavy & & No & Slight [2]
\end{tabular}

a Performed according to the scheme by Honda as described in the "Methods" section

\section{Spectrophotometer measurements}

Results from the spectrophotometric analysis correspond to the visual observations. The changes in the $\mathrm{L}^{*}, \mathrm{a}^{*}, \mathrm{~b}^{*}$ values for the well processed photographs after degradation at $50{ }^{\circ} \mathrm{C}$ and $70 \% \mathrm{RH}$ were small, while after degradation at $50{ }^{\circ} \mathrm{C}$ and $90 \% \mathrm{RH}$ they were more significant for both of the fibre based papers. Differences in the $b^{*}$ values were particularly noticeable, which corresponds to the visually observed yellowing.

The insufficiently washed photographs on fibre based paper behaved differently. In comparison to the well processed samples the changes in the $b^{*}$ values were accompanied by significant changes in the $L^{*}$ values, corresponding to a more yellow but darker appearance. They also tended to have a greater $\Delta \mathrm{a}^{*}$ in relation to $\Delta \mathrm{b}^{*}$ and consequently appear more red. This was true for ageing at both 70 and $90 \% \mathrm{RH}$ and was most pronounced in the mid tones, particularly around step 8 , where we see the least influence from the optical brightening agent. These results are illustrated in Fig. 3 using $\Delta \mathrm{L}^{*}, \Delta \mathrm{a}^{*}$ and $\Delta \mathrm{b}^{*}$.

Reflectance spectra were also taken. They showed similar effects with greater reflectance in the red at 480$740 \mathrm{~nm}$ in the insufficiently washed samples, see Fig. 4.

These results indicate that a more yellow colour may correspond to the migration of image silver whilst a more reddish colour may correspond to the presence of residual fixer, providing a better understanding of the causes of damage, without resorting to destructive testing.

The resin coated photographs behaved differently, with less significant colour change measured or visually perceived in the insufficiently washed photographs aged at $50{ }^{\circ} \mathrm{C}$ and $70 \% \mathrm{RH}$ or the insufficiently washed and well processed photographs aged at $50{ }^{\circ} \mathrm{C}$ and $90 \% \mathrm{RH}$. Contrary to the fibre based samples, the well processed resin coated photographs aged at $50{ }^{\circ} \mathrm{C}$ and $90 \% \mathrm{RH}$ darkened more than the insufficiently washed resin coated samples aged at both $70 \% \mathrm{RH}$ and $90 \% \mathrm{RH}$. Despite this the insufficiently washed had greater $\Delta \mathrm{a}^{*}$ readings than $\Delta \mathrm{b}^{*}$, particularly in steps 14 , 11 and 8 , corresponding to a redder appearance.

\section{Transmission electron microscopy}

The results of TEM show that in the well-processed photographs, exposure to high relative humidity leads to image silver migration and yellowish discolouration, while in the insufficiently washed photographs, with quite extreme levels of residual thiosulfate, silver migration is less prevalent and the reddish discolouration is due to silver sulfide formation. The photographs on resincoated papers represent an intermediate scenario.

Transmission electron microscopy images of the fibre based matt well processed test photographs, see Fig. 5 give an indication of the behaviour of the silver image particles under the conditions of artificial degradation. After ageing at $50{ }^{\circ} \mathrm{C}$ and $70 \% \mathrm{RH}$, there is evidence of silver migration in the well processed photographs on all paper types. In the fibre based papers there were small colloidal silver particles $(0-10 \mathrm{~nm})$ quite widely and evenly dispersed around the silver filaments. This was significantly more pronounced in the samples aged at $50{ }^{\circ} \mathrm{C}$ and $90 \% \mathrm{RH}$, see Table 3 .

The insufficiently washed samples behaved differently to the well processed photographs, see Fig. 5. Although discolouration was observed in both well processed and insufficiently washed photographs, TEM images showed increased homogeneity of the silver filament in the insufficiently washed photographs and only a limited amount of colloidal silver, see Table 3 . This was again particularly pronounced at $50{ }^{\circ} \mathrm{C}$ and $90 \% \mathrm{RH}$ indicating that these conditions silver sulfide was inhibiting silver migration. The effects of artificial ageing at $50{ }^{\circ} \mathrm{C}$ and $70 \% \mathrm{RH}$ as shown later are probably more similar to naturally aged photographs with residual sulfur.

In the resin coated papers the silver filaments were not quite as homogeneous and large amounts of colloidal silver were seen in the upper layers of the cross section at both $50{ }^{\circ} \mathrm{C}$ and $70 \%$ and $50{ }^{\circ} \mathrm{C}$ and $90 \%$. The sulfur appears to have had less impact on the physical shape of the silver filaments so colour differences may therefore be due to very thin layers of silver sulfide or colloidal silver 

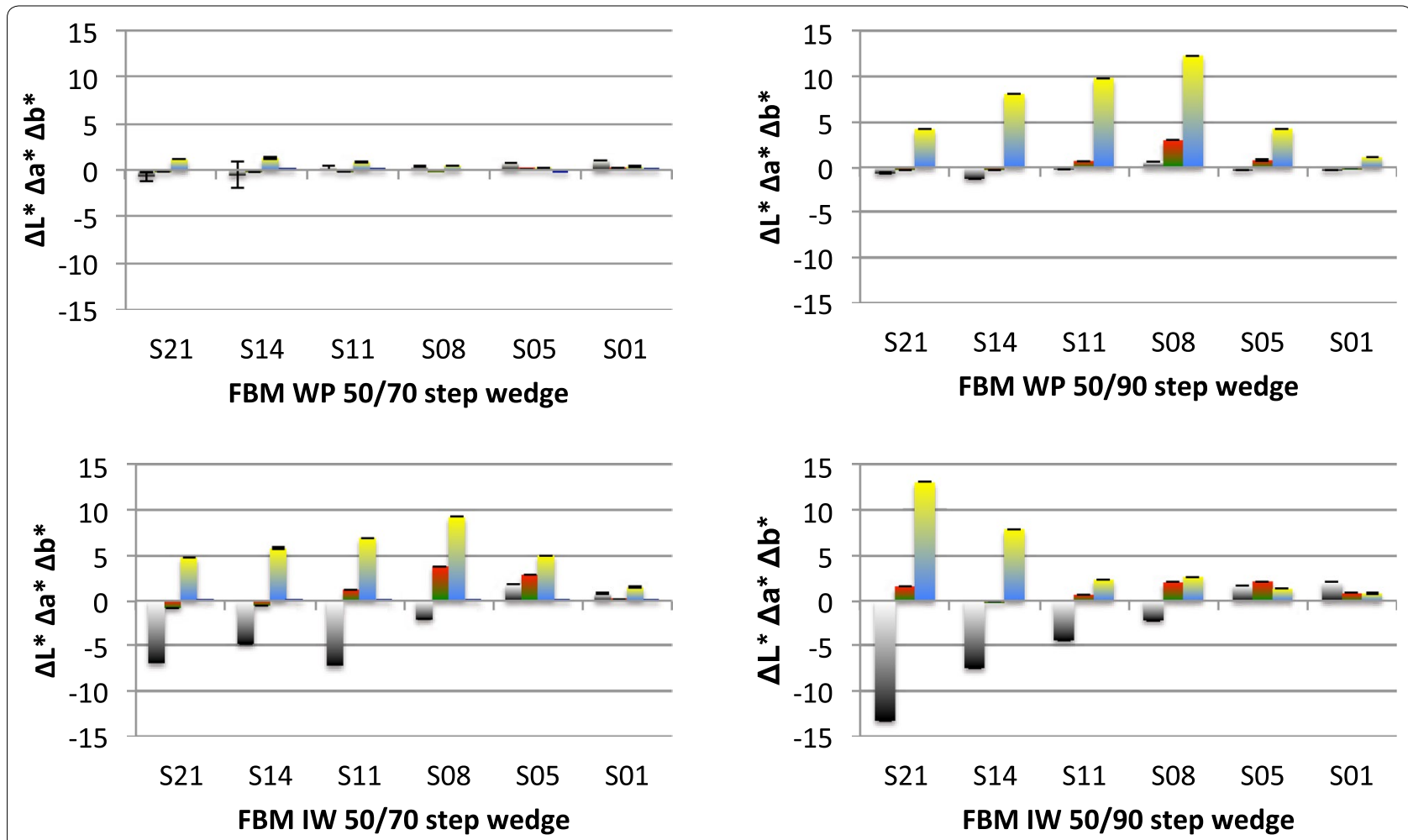

Fig. 3 The $\Delta L^{*} \Delta a^{*} \Delta b^{*}$ values for the well processed (WP) and insufficiently washed (IW) fibre based matt test photographs. Top left: well processed aged at $50{ }^{\circ} \mathrm{C}$ and $70 \% \mathrm{RH}$, top right: well processed aged at $50^{\circ} \mathrm{C}$ and $90 \% \mathrm{RH}$, bottom left: insufficiently washed aged at $50{ }^{\circ} \mathrm{C}$ and $70 \% \mathrm{RH}$, bottom right: insufficiently washed aged at $50^{\circ} \mathrm{C}$ and $90 \% \mathrm{RH}$

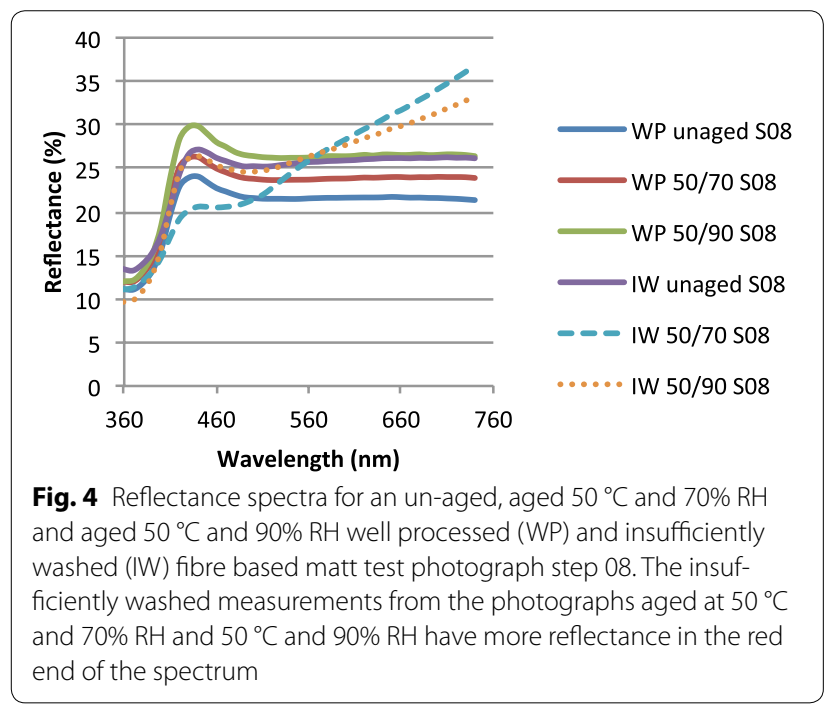

sulfide as described by Ware [9]. The impacts of artificial ageing on the insufficiently washed photographs on resin coated paper may also reflect a more realistic scenario, comparable to that found in a real collection, with a less extreme quantity of residual thiosulfate leading to silver migration alongside silver sulfide formation and subtler colour differences.

Larger colloidal particles responsible for photographs appearing red (25-35 nm) and purple-red (35-45 nm) [9] were not found to be more evident in the insufficiently washed photographs than the well processed photographs, indicating size of the colloidal silver was not solely responsible for perceived colour differences.

\section{ATR FTIR spectroscopy}

Fourier transform infra-red spectroscopy was used to investigate changes to the gelatine structure. Analysis of four pairs of fibre-based glossy photographs, including both well processed and insufficiently washed samples before and after ageing at $50{ }^{\circ} \mathrm{C}$ and both $70 \%$ and $90 \%$ $\mathrm{RH}$ was performed. In the insufficiently washed samples, a small increase in the peak ratios between amide I and II was observed after ageing at $50{ }^{\circ} \mathrm{C}$ and $70 \% \mathrm{RH}$ which could suggest some deterioration of the gelatine, most likely due to the additional sulfur. However, more repeated analysis is necessary to assess the significance of these measurements. In summary while a contribution to discolouration from degradation of gelatine cannot be ruled out, the evidence in previous work and in this work 


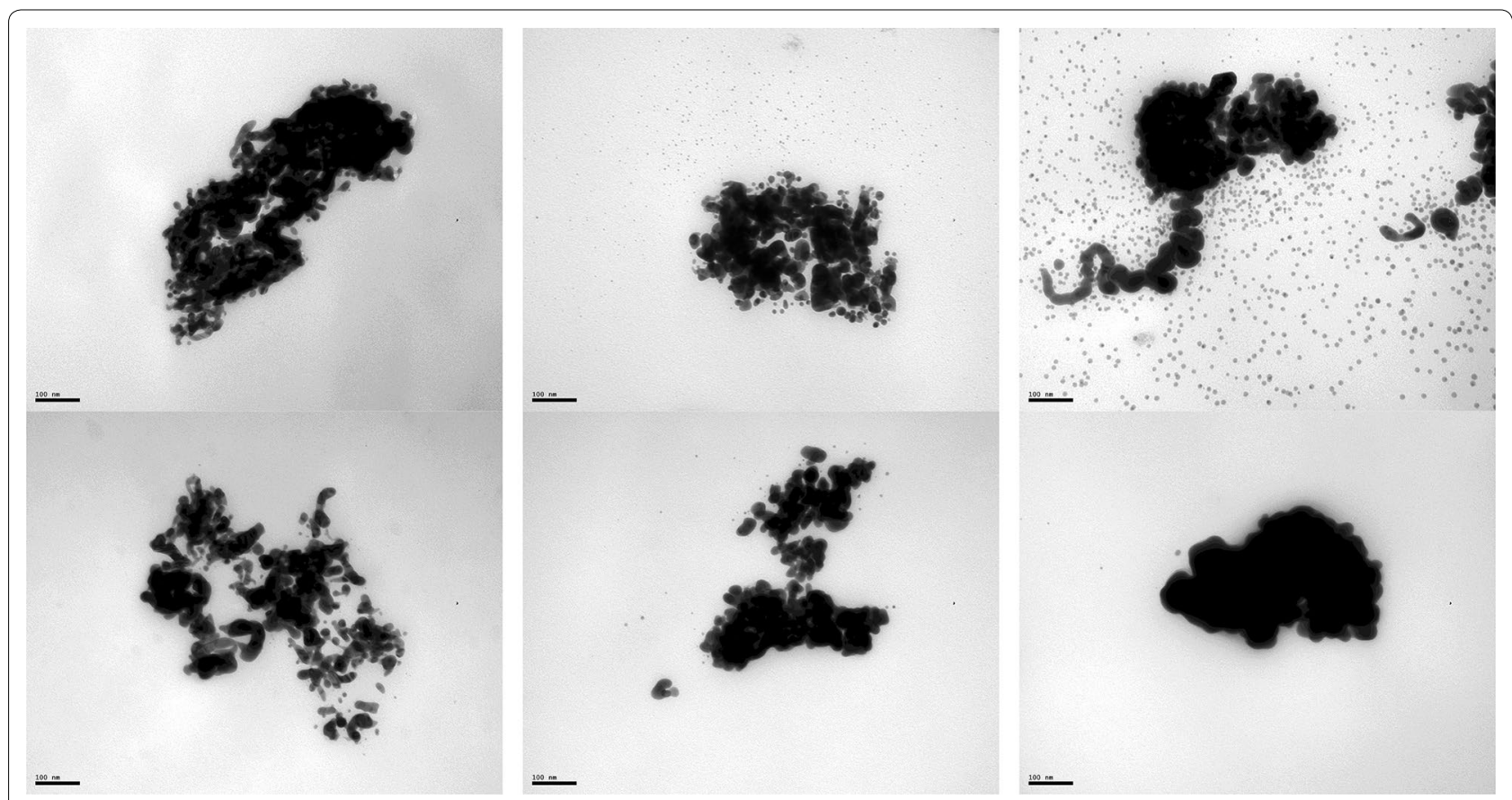

Fig. 5 Transmission electron microscopy pictures of the fibre based matt test photographs step 5 at $\times 150 \mathrm{k}$ (scale bar measures $100 \mathrm{~nm}$ ). Top row left to right: well processed un-aged, aged $50{ }^{\circ} \mathrm{C}$ and $70 \% \mathrm{RH}$ and aged $50{ }^{\circ} \mathrm{C}$ and $90 \% \mathrm{RH}$. Bottom row left to right: insufficiently washed un-aged, aged $50{ }^{\circ} \mathrm{C}$ and $70 \% \mathrm{RH}$ and aged $50{ }^{\circ} \mathrm{C}$ and $90 \% \mathrm{RH}$

Table 3 The maximum, minimum and average number of colloidal silver particles found in TEM images of test fibre based matt photographs processed and aged differently

\begin{tabular}{lccc}
\hline Sample & Maximum $^{\mathbf{a}}$ & Minimum $^{\mathbf{a}}$ & Average $^{\mathbf{a}}$ \\
\hline Well processed un-aged & 8 & 6 & $4^{\mathrm{b}}$ \\
Well processed aged 50/70 & 208 & 9 & $27^{c}$ \\
Well processed aged 50/90 & 826 & 124 & $257^{c}$ \\
Insufficiently washed un-aged & 26 & 14 & $10^{\mathrm{d}}$ \\
Insufficiently washed aged 50/70 & 11 & 1 & $3^{c}$ \\
Insufficiently washed aged 50/90 & 6 & 0 & $1^{c}$
\end{tabular}

a Relates to number of colloidal silver particles, defined as having a diameter of $0-25 \mathrm{~nm}$

b Average of 3 values

c Average of 9 values

d Average of 2 values

certainly provides evidence of the link between silver migration, silver sulfide formation and discolouration.

\section{How do the naturally and artificially degraded samples relate to one another? Natural and artificial degradation}

The historical samples, see Fig. 6, were compared to the artificially aged samples to determine the validity of the artificial ageing. The historical photographs are probably all twentieth century images. "Aeroplane" and "Crumpled manuscript" have dates written on the verso, see Table 1. The papers are all fibre based and have slightly different paper tones, see Table 4. "Street scene" has both yellowed highlights and a yellowed paper tone which give the impression of overall yellowing but the shadows are still neutral grey. The iodine potassium iodide test indicated a starch based matting agent. The silver and hypo spot tests showed a lack of silver or residual fixer: this combined with the lack of yellowing in the shadows and the mirroring indicates it is yellowed due to humidity. "Ceremony" tested 'heavy' to residual fixer and 'perceptible' to silver indicating the chocolate brown image tones are probably due to the presence of silver sulfide. "Aeroplane" had a 'slight' reaction to the residual fixer test and barely perceptible yellowing whilst "Crumpled manuscript" had a 'barely perceptible' reaction to the residual fixer test and imperceptible yellowing. "Crumpled manuscript" has an optical brightening agent and a slightly pinkish hue.

Transmission electron microscopy images showed that natural ageing caused by humidity, pollutants or residual chemistry has caused a breakdown in the image silver, see Fig. 7, similar to that seen in the test photographs. There was greater variation in the size and shape of the historical silver filaments than the test photographs and the silver filaments were generally more rounded with fewer long strands. All the samples had some colloidal silver. In trying to make a direct comparison between the silver 


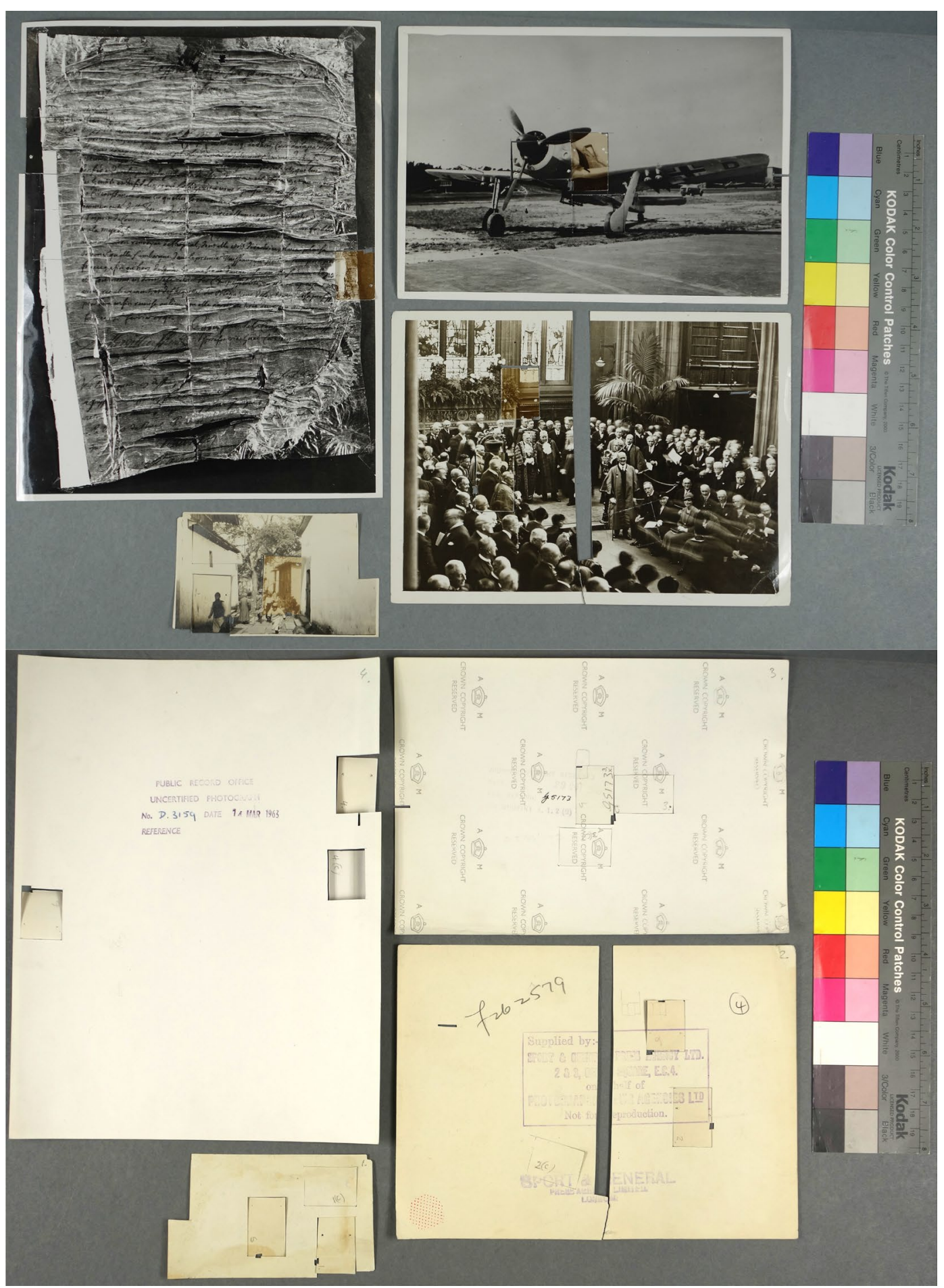

Fig. 6 Historical samples on fibre-based papers. Clockwise from top left: "Crumpled manuscript", "Aeroplane,, "Ceremony", "Street scene" note: These photographs have been used for a separate ageing experiment and the dis-coloured rectangles can be disregarded

filaments of the historical and the test photographs, "Street scene" had small, rounded clumps, widely dispersed and relatively homogeneous with a significant formation of colloidal silver at the surface of the cross section. The presence of relatively large amounts of colloidal silver in the upper layer of the cross section was more similar to 
Table 4 Visual observations and spot test results of the historical photographs

\begin{tabular}{|c|c|c|c|c|c|c|}
\hline \multirow{2}{*}{$\begin{array}{l}\text { Sample name } \\
\text { and date }\end{array}$} & \multicolumn{4}{|c|}{ Visual observations $^{a}$} & \multicolumn{2}{|l|}{ Spot tests } \\
\hline & Border & Image & Verso & Comments image & Silver test & $\begin{array}{l}\text { Residual fixer (thio- } \\
\text { sulfate) }\end{array}$ \\
\hline $\begin{array}{l}\text { "Street scene" (S) early } \\
\text { 20th century on } \\
\text { cream fibre based } \\
\text { matt paper }\end{array}$ & Moderate & Moderate & Moderate & $\begin{array}{l}\text { Yellowed in highlights } \\
\text { and mid tones. } \\
\text { Neutral grey in } \\
\text { shadows. Mirroring } \\
\text { on shadow areas }\end{array}$ & No & No \\
\hline $\begin{array}{l}\text { "Ceremony" (C) 20th } \\
\text { century on cream } \\
\text { fibre based glossy } \\
\text { paper }\end{array}$ & Slight & Moderate & Moderate & $\begin{array}{l}\text { Image is choco- } \\
\text { late brown hue } \\
\text { throughout: } \\
\text { thought to be yel- } \\
\text { lowing }\end{array}$ & Perceptible & Heavy [4] \\
\hline $\begin{array}{l}\text { "Aeroplane" (A) } \\
\text { 29/10/1945 on off } \\
\text { white fibre based } \\
\text { glossy paper }\end{array}$ & Barely perceptible & Barely perceptible & Barely perceptible & & Barely perceptible & Slight [2] \\
\hline $\begin{array}{l}\text { "Crumpled manu- } \\
\text { script" (CM) } \\
14 / 03 / 1963 \text { on } \\
\text { white (OBA) fibre } \\
\text { based glossy paper }\end{array}$ & Imperceptible & Imperceptible & Barely perceptible & & No & Barely perceptible [1] \\
\hline
\end{tabular}

a Performed according to the scheme by Honda as described in the "Methods" section

the well processed test photos aged at $50{ }^{\circ} \mathrm{C}$ and $90 \% \mathrm{RH}$. "Ceremony's" filaments were generally composed of more fragments. This fragmentation of the clumps of silver filaments is seen more often in the insufficiently washed unaged test photographs but the proximity of colloidal silver around the filaments closest to the baryta layer was more similar to the insufficiently washed test photographs aged at $50{ }^{\circ} \mathrm{C}$ and $70 \% \mathrm{RH}$ (particularly evident in the fibre based glossy photographs, see https://doi.org/10.6084/ m9.figshare.5213074.v1) whilst the extent of the colloidal silver was more similar to the well processed test photos aged at $50{ }^{\circ} \mathrm{C}$ and $90 \% \mathrm{RH}$. Two processes are at work here. As the sulfur content of "Ceremony" was probably significantly smaller than the insufficiently washed test samples and the influence of humidity in this process probably great it seems reasonable to expect "Ceremony' would have both fragmented filaments and colloidal silver. The filaments in "Aeroplane" had an appearance between those of the well processed and insufficiently washed test samples aged at $50{ }^{\circ} \mathrm{C}$ and $70 \% \mathrm{RH}$ with some migration of image silver present at the top of the cross section. The filaments in "Crumpled manuscript" were between the well processed un-aged and aged at $50{ }^{\circ} \mathrm{C}$ and $70 \% \mathrm{RH}$ with the least amount of colloidal silver.

\section{Perceived colour and silver particle migration in the historical samples}

The historic photos were studied to see if the relationships between colour change and silver particle migration were consistent with the test photographs, see Table 5 .
The greater the visually observed yellowing the greater the number of colloidal silver particles for the historical samples. "Ceremony" had the greatest number of colloidal silver particles and also the greatest degree of discoloration throughout its image tones despite the presence of residual sulfur. The proximity of more colloidal silver adjacent to the baryta layer suggests the retention of thiosulfate in this area has led to silver ionisation.

\section{Perceived colour and the presence of residual sulfur}

The range of paper and image tones of the historical samples make direct comparisons challenging. To help with this colour measurements were taken of their versos (in absence of a white border on the recto) and a light, medium and dark tone on the recto. The L*a*b* and status A (B) densitometry of the historical samples, see Fig. 8, were compared to the residual fixer spot tests. Those samples which tested positive to residual sulfur; "Ceremony", and to a lesser degree "Aeroplane", showed greater positive $\mathrm{a}^{*}$ in relation to $\mathrm{b}^{*}$ in the mid and dark tones, and in comparison to "Street scene" which had neutral tones in the dark areas. This was more clearly seen in the reflectance spectra, where both "Ceremony" and" Aeroplane" had steeper curves towards the red end of the spectrum than "Street scene" in the medium and dark areas of the image, see Fig. 8. "Ceremony" saw the most dramatic changes in red reflectance from the verso paper colour to the image tone.

"Crumpled manuscript", the sample with optical brightener and a pinkish hue had high $\mathrm{a}^{*}$ which decreased 


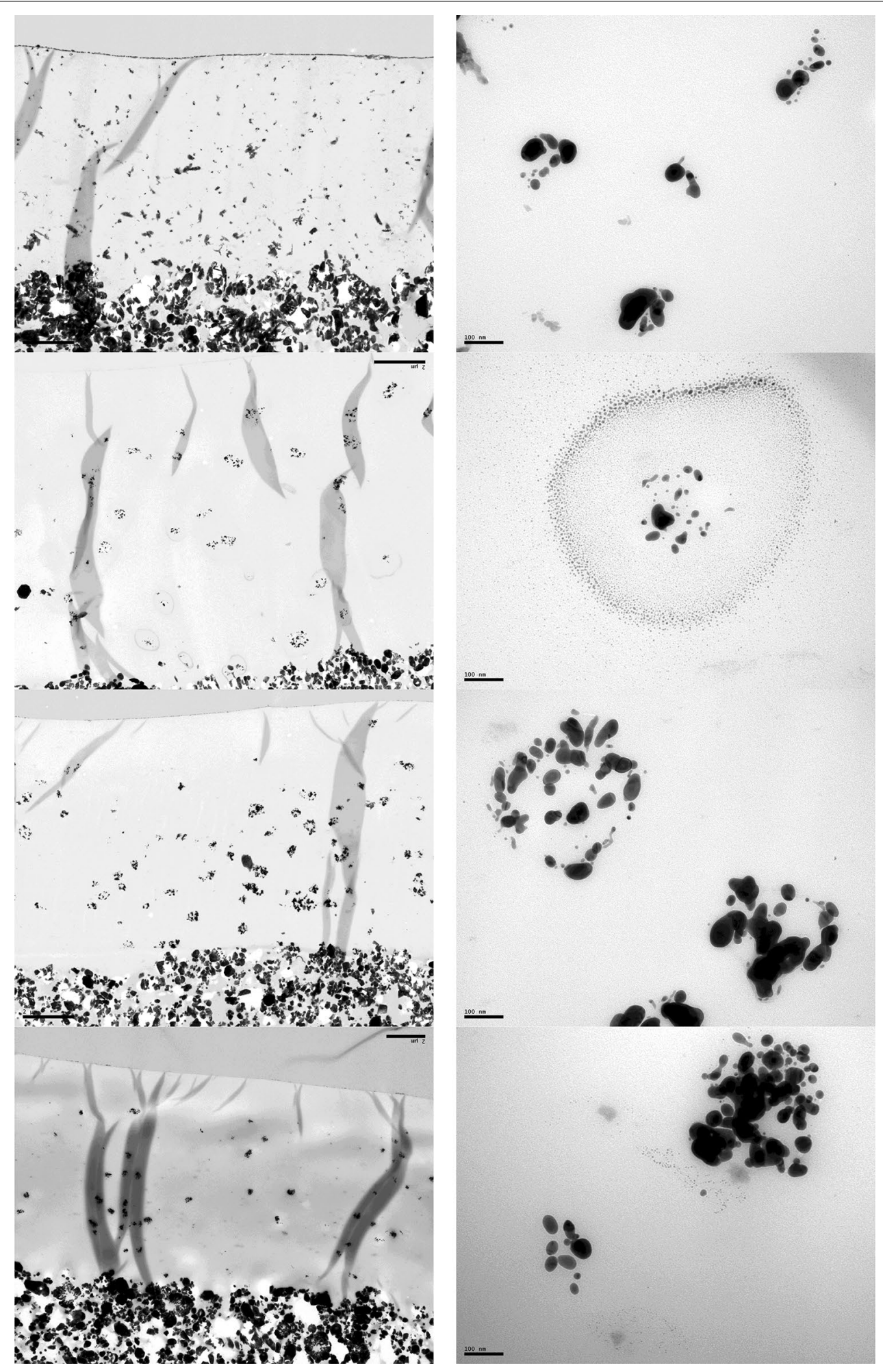

Fig. 7 Transmission electron microscope images of the historical samples. Left column $\times 10$, right column $\times 150 \mathrm{k}$ (scale bar measures $100 \mathrm{~nm}$ ). Top row: "Street scene", second row: "Ceremony", third row: "Aeroplane", fourth row: "Crumpled manuscript" 
Table 5 The maximum, minimum and average number of colloidal silver particles found in TEM images of historical photographs both surrounding the silver particles and in the upper layer of the cross section

\begin{tabular}{lccc}
\hline Sample & Maximum $^{\mathbf{a}}$ & Minimum $^{\mathbf{a}}$ & Average $^{\mathbf{a}}$ \\
\hline Street scene & 397 & 6 & $130^{\mathrm{b}}$ \\
Ceremony & 2840 & 80 & $1197^{\mathrm{c}}$ \\
Aeroplane & 281 & 4 & $75^{\mathrm{d}}$ \\
Crumpled manuscript & 201 & 3 & $37^{\mathrm{c}}$ \\
\hline
\end{tabular}

a Relates to number of colloidal silver particles, defined as having a diameter of $0-25 \mathrm{~nm}$

b Average of 9 values (six filaments and three from the upper layer of the cross section)

c Average of 11 values (nine filaments and two from the upper layer of the cross section)

d Average of 12 values (nine filaments and three from the upper layer of the cross section)

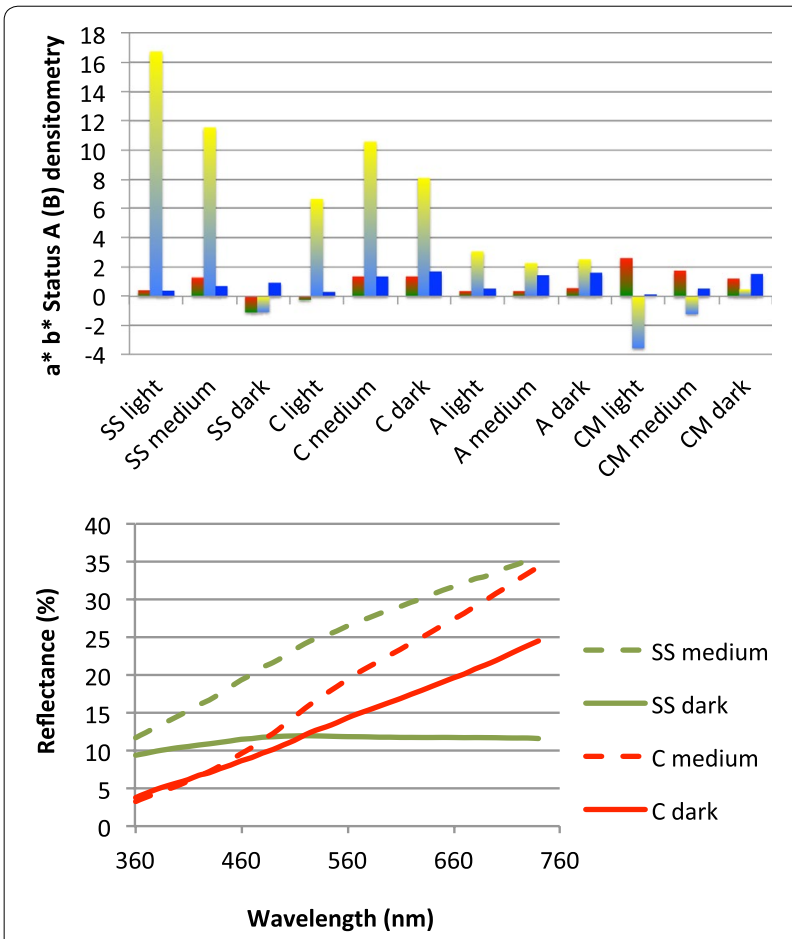

Fig. 8 Top: the $a^{*} b^{*}$ and status $A(B)$ results for the historical photographs. Bottom: the reflectance spectra of the dark and medium tones of "Street scene" and "Ceremony". The spectra show an increased red reflectance in the sulfur affected photograph

towards the dark areas. However, as the spot test shows, "Crumpled manuscript" does not contain residual thiosulfate. In this case a high $\mathrm{a}^{*}$ value and a spectrum showing reflectance in the red region would be misleading. The reason for the pinkish hue in this photograph is not known and illustrates that a range of methods are needed in conjunction with spectrophotometry to diagnose sulfur affected photographs, for example: reference photographic sample books, silver and hypo spot test and multiple colour measurements from different parts of the photograph on much larger sample sets of similar ages and paper types.

Spectrophotometry was useful in detecting the dark and neutral tones of "Street scene" despite its overall yellowing. This could be useful a diagnostic tool for non experts to study the extent of yellowing in a photographic image.

This limited historical sample set indicates it would be worth investigating if $\mathrm{a}^{*}$ and an increased red reflectance are greater in sulfur affected images on a larger set of historical photographs.

\section{Conclusions}

This research shows that in the case of artificially aged test photographs, while image silver migration and silver sulfide formation both give rise to discolouration in silver gelatine photographs, this discolouration is perceived differently, with silver migration causing a yellowish appearance and silver sulfide formation causing a reddish appearance. This can be seen with the naked eye but also quantified using $L^{*} a^{*} b^{*}$, status A (B) densitometry and reflectance spectra, allowing different degradation mechanisms to be identified. The historical photographs were more complicated.

Well processed test photographs degraded at $50{ }^{\circ} \mathrm{C}$ and $90 \% \mathrm{RH}$ appeared visually yellow, had significant increases in the measured $\mathrm{b}^{*}$ values and substantial migration of the silver particles visible in TEM images. A large number of colloidal silver particles with diameters of $0-25 \mathrm{~nm}$ were formed in these photographs and surface plasmon resonance associated with these particles is believed to be the cause of the observed yellowing.

In contrast, the insufficiently washed test photographs with large quantities of residual sulfur appeared either reddish-brown or purplish brown after degradation at $50{ }^{\circ} \mathrm{C}$ and 70 and $90 \% \mathrm{RH}$ respectively and TEM images of the fibre based test photographs showed little or no migration of silver particles and almost no colloidal silver particles with diameters of 0-25 $\mathrm{nm}$. Before artificial ageing the filaments were often more fragmented but with ageing became increasingly homogeneous indicating colour change was probably due to silver sulfide formation around the silver filaments. Colour measurements showed these photographs had both greater $\mathrm{a}^{*}$ and smaller $L^{*}$ values than the well processed photographs and consequently appeared both redder but also darker.

Artificial ageing of the well processed test photographs at both $50{ }^{\circ} \mathrm{C}$ and $70 \% \mathrm{RH}$ and $50{ }^{\circ} \mathrm{C}$ and $90 \% \mathrm{RH}$ and the insufficiently washed photographs at $50{ }^{\circ} \mathrm{C}$ and $70 \%$ 
RH was found to produce the same or similar migration of image silver when compared to naturally aged historical photographs with one significant exception: the quantity of residual sulfur in the test photographs resulted in smaller quantities of colloidal silver when compared to the sulfur affected historical photographs. The quantity of residual sulfur in the test photographs was extreme and it would be worth more carefully imitating degrees of residual sulfur for future work.

In the case of historical photographs, colour differences between well processed and insufficiently washed photographs were harder to distinguish. The historical photographs with residual fixer had slightly greater $\mathrm{a}^{*}$ values than the well processed as well as an increased red reflectance. This was more noticeable when colour measurements of the verso were compared. Colour measurements were also found to more clearly identify if a photograph was partially or completely yellowed. This would be useful for both non specialists or conservators without significant experience of photographs when surveying the extent of chemical damage in photographic collections. This investigation indicates colorimetry could be useful in identifying deterioration processes in combination with other techniques such as silver and hypo spot tests and multiple colour measurements from different parts of the photograph on much larger sample sets of similar ages and paper types.

\section{Authors' contributions}

Scientific data gathering, analysis and manuscript draft was carried out by JM. Preparation of the manuscript was carried out by JM and KC. Both authors read and approved the final manuscript.

\section{Author details}

${ }^{1}$ The National Archives, Kew, Richmond, Surrey, UK. ${ }^{2}$ UCL Institute for Sustainable Heritage, Bartlett School of Environment, Energy and Resources, University College London, London, UK.

\section{Acknowledgements}

I would particularly like to thank Nancy Bell ACR for suggesting I undertake the MRes in Heritage Science at University College London and Mark Turmaine for his help with the TEM sample preparation.

\section{Competing interests}

Both authors declare that they have no competing interests.

\section{Availability of data and materials}

The datasets supporting the conclusions of this article are available in the Figshare repository:

Images of the test photographs: https://doi.org/10.6084/ m9.figshare.5212624.v1.

Visual observations and spot test results test photographs and historical photographs: https://doi.org/10.6084/m9.figshare.5212795.v1.

Colour measurements $\Delta \mathrm{L}^{*} \Delta \mathrm{a}^{*}$ and $\Delta \mathrm{b}^{*}$ for the test photographs: https:// doi.org/10.6084/m9.figshare.5212804.v1.

Transmission electron micrographs of the test photographs: https://doi. org/10.6084/m9.figshare.5213074.v1.

Transmission electron micrographs of the historical photographs: https:// doi.org/10.6084/m9.figshare.5213236.v1.

\section{Consent for publication}

No details, images, or videos relating to individual participants are included in this research.

\section{Declarations}

We confirm that this work is original and has not been published elsewhere, nor is it currently under consideration for publication elsewhere.

\section{Ethics approval and consent to participate}

No human subjects, human material or human data were used in this research.

\section{Funding}

This paper has resulted from work completed during a Research Masters in Heritage Science at UCL Institute of Sustainable Heritage. The Research Masters was funded by The National Archives, U.K.

\section{Publisher's Note}

Springer Nature remains neutral with regard to jurisdictional claims in published maps and institutional affiliations.

Received: 10 March 2017 Accepted: 9 October 2017

Published online: 01 November 2017

\section{References}

1. Reilly JM. The component materials of 19th-century prints and their forms of deterioration. Care and identification of 19th century photographic prints. Fourth. Eastman Kodak Company; 2009. p. 14-32.

2. Dune C, Grinde L, Wiegandt R. Characterization of black-and-white silver gelatin fiber-based photographic prints. Top Photogr Preserv. 2005:11:38-56.

3. Parsons TF, Gray GG, Crawford IH. To RC or not to RC. In: Hess Norris D, Guitierrez JJ, editors. Issues in the conservation of photographs. Los Angeles: Getty Publications; 2010. p. 171-87.

4. Hodgson A. Silver halide materials: general emulsion properties. In: Peres MR, editor. The focal encyclopedia of photography. Oxford: Focal Press; 2007. p. 641-9.

5. Hendriks KB. On the mechanism of image silver degradation. In: Hess Norris D, Guitierrez JJ, editors. Issues in the conservation of photographs. Los Angeles: Getty Publications; 2010. p. 227-35.

6. Torigoe M, Ohmura K, Yagami S, Iwano H. Long-term preservation of black and white photographs. In: Hess Norris D, Guitierrez JJ, editors. Issues in the conservation of photographs. Los Angeles: Getty Publications; 2010. p. 206-11.

7. Weaver G. A guide to fiber-based gelatin silver print condition and deterioration. Gawain Weaver Art Conservation; 2013. http://gawainweaver. com/images/uploads/Weaver_Guide_to_Gelatin_Silver.pdf. Accessed 2 Mar 2017.

8. Oldenburg SJ. Silver nanoparticles: properties and applications. Sigma Aldrich Materials Science. 2010. http://www.sigmaaldrich.com/materialsscience/nanomaterials/silver-nanoparticles.html. Accessed 31 Mar 2015.

9. Ware M. Appendix III. The colours of silver images. Mechanisms of image deterioration in early photographs. Bradford: National Museum Pictureville; 1994. p. 71-5.

10. Henn RW, Wiest DG. Microscopic spots on processed microfilm. Photogr Sci Eng. 1963;7:253-61.

11. James TH. The stability of silver filaments. In: Hess Norris D, Guitierrez JJ, editors. Issues in the conservation of photographs. 1st ed. Los Angeles: Getty Publications; 2010. p. 116-38.

12. McCamy CS, Pope Cl. Redox blemishes-their cause and prevention. In: Hess Norris D, Guitierrez JJ, editors. Issues in the conservation of photographs. Los Angeles: Getty Publications; 2010. p. 139-47.

13. Skillman DC, Berry CR. Effect of particle shape on the spectral absorption of colloidal silver in gelatine. J Chem Phys. 1968:48:3297-304.

14. Kerker M. The optics of colloidal silver. J Colloid Interface Sci. 1985:105:297-314. 
15. Hamilton JF, Urbach F. The mechanism of the formation of the latent image. In: Mees CEK, James TH, editors. The theory of the photographic process. 3rd ed. London: Collier-Macmillan Limited; 1966. p. 87-119.

16. Perrin FH. The structure of the developed image. In: Mees CEK, James TH, editors. The theory of the photographic process. 3rd ed. London: CollierMacmillan Limited; 1966. p. 499-551.

17. Berry CR, Loveland RP. The silver halide grains. In: Mees CEK, James TH, editors. The theory of the photographic process. 3rd ed. London: CollierMacmillan Limited; 1966. p. 31-44.

18. BS ISO 18929. Imaging materials-wet-processed silver-gelatin type black-and-white photographic reflection prints—specifications for dark storage. 2012.

19. Reilly JM, Kennedy N, Black D, Van Dam T. Image structure and deterioration in albumen prints. In: Hess Norris D, Guitierrez JJ, editors. Issues in the conservation of photographs. Los Angeles: Getty Publications; 2010. p. 306-19.

20. Nishimura W, Reilly JM, Adelstein P. Improvements to the photographic activity test in ANSI Standard IT9.2. In: Hess Norris D, Guitierrez JJ, editors. Issues in the conservation of photographs. Los Angeles: Getty Publications; 2010. p. 155-70.

21. Odegaard N, Carroll S, Zimmt WS. Material characterization tests for objects of art and archaeology. London: Archetype Publications; 2005. p. 230. http://books.google.com/books?id=BaZ1QgAACAAJ\&pgis=1. Accessed 30 Nov 2013.
22. Lavédrine B. Appendix I. Formulary. A guide to the preventative conservation of photographs. Los Angeles: Getty Publications; 2003. p. 239-43.

23. Directorate-General for Research and Innovation. Improved damage assessment of parchment. Larson R, editor. Copenhagen: European Commission; 2007.

24. Honda C. A new method of predicting the oxidative discoloration of silver images. Imaging Sci Technol. 1998;42:148-52.

25. Socrates G. Infrared and Raman characteristics group frequencies tables and charts. Third. Chichester: Wiley; 2001. p. 246.

26. Swan A. Problems in the conservation of silver gelatin prints. In: Hess Norris D, Gutierrez J, editors. Issues in the conservation of photographs. Los Angeles: Getty Conservation Institute; 1981. p. 533-54.

27. Lavédrine B. The vulnerability of photographs. A guide to the preventative conservation of photographs. Los Angeles: Getty Conservation Institute; 2003. p. 3-29.

28. Weyde E. Das Copyrapid-Verfahren der Agfa. Mitt Forschungslab Agfa; 1955. p. 262-6.

29. Lavédrine B. Photographs of the past: process and preservation. Los Angeles: Getty Publications; 2009.

\section{Submit your manuscript to a SpringerOpen ${ }^{\circ}$ journal and benefit from:}

- Convenient online submission

- Rigorous peer review

- Open access: articles freely available online

- High visibility within the field

- Retaining the copyright to your article

Submit your next manuscript at $\boldsymbol{\nabla}$ springeropen.com 